\title{
Controlled Clinical Trial of Selective Decontamination for the Treatment of Severe Acute Pancreatitis
}

Ernest J. T. Luiten, M.D., ${ }^{*}$ Wim C. J. Hop, M.Sc., † Johan F. Lange, M.D., Ph.D., $\neq$ and

Hajo A. Bruining, M.D., Ph.D.*

From the Department of Surgery, University Hospital Rotterdam-Dijkzigt and Erasmus

University, ${ }^{*}$ the Department of Epidemiology and Biostatistics, Erasmus University, $\dagger$ and the

Department of Surgery, St. Clara Hospital, $\ddagger$ Rotterdam, the Netherlands

\section{Objective}

A randomized, controlled, multicenter trial was undertaken in 102 patients with objective evidence of severe acute pancreatitis to evaluate whether selective decontamination reduces mortality.

\section{Summary Background Data}

Secondary pancreatic infection is the major cause of death in patients with acute necrotizing pancreatitis. Controlled clinical trials to study the effect of selective decontamination in such patients are not available.

\section{Methods}

Between April 22, 1990 and April 19, 1993, 102 patients with severe acute pancreatitis were admitted to 16 participating hospitals. Patients were entered into the study if severe acute pancreatitis was indicated, on admission, by multiple laboratory criteria (Imrie score $\geq 3$ ) and/or computed tomography criteria (Balthazar grade $\mathrm{D}$ or $\mathrm{E}$ ). Patients were randomly assigned to receive standard treatment (control group) or standard treatment plus selective decontamination (norfloxacin, colistin, amphotericin; selective decontamination group). All patients received full supportive treatment, and surveillance cultures were taken in both groups.

\section{Results}

Fifty patients were assigned to the selective decontamination group and 52 were assigned to the control group. There were 18 deaths in the control group (35\%), compared with 11 deaths $(22 \%)$ in the selective decontamination group. (adjusted for Imrie score and Balthazar grade: $p=0.048$ ). This difference was mainly caused by a reduction of late mortality ( $>2$ weeks) due to significant reduction of gram-negative pancreatic infection $(p=0.003)$. The average number of laparotomies per patient was reduced in patients treated with selective decontamination $(p<0.05)$. Failure of selective decontamination to prevent secondary gram-negative pancreatic infection with subsequent death was seen in only three patients $(6 \%)$ and transient gram-negative pancreatic infection was seen in one (2\%). In both groups of patients, all gram-negative aerobic pancreatic infection was preceded by colonization of the digestive tract by the same bacteria. 


\section{Conclusion}

Reduction of gram-negative colonization of the digestive tract, preventing subsequent pancreatic infection by means of selective decontamination, significantly reduces morbidity and mortality in patients with severe acute necrotizing pancreatitis.

Despite improvement in surgical strategies, the mortality of patients with acute necrotizing pancreatitis remains high, between $20 \%$ and $70 \% .{ }^{1-8}$ Infection of pancreatic necrosis is the most important cause of late mortality in severe acute pancreatitis. ${ }^{3,7,9-13}$ The value of prophylactic antibiotics has not been clearly demonstrated in patients with severe acute pancreatitis and possibly is due to patient selection, inadequate spectrum, insufficient doses, or tissue penetration. ${ }^{12.14-17}$

Intravenous antibiotics, which penetrate the pancreasblood barrier, may not protect the necrotic nonperfused areas in and around the inflamed pancreas against infection. The route by which sterile pancreatic necrosis becomes infected is not yet known. Experimental studies and clinical observations have suggested that translocation of bacteria toward the pancreas occurs hematogenously, ${ }^{18.19}$ transmurally through the colon, ${ }^{20-22}$ via lymphogenous routes, ${ }^{20,23}$ via ascites, ${ }^{19,23}$ and through bile ${ }^{24}$ and duodenal chyme reflux. ${ }^{25}$ Because gram-negative bacteria-predominantly isolated from the pancreatic necrosis-are of enteric origin, the source of the translocating bacteria probably is the intestine. . $^{27,9,10,14,22,23,26,27}$ Prevention of translocation by intraluminal elimination of aerobic gram-negative micro-organisms in the intestinal tract may be an effective method to prevent pancreatic necrosis from becoming infected. In a controlled experimental study on rats with bile-salt-induced pancreatitis, Lange et al. demonstrated a significant reduction of mortality in rats treated with intestinal lavage and intraluminal instillation of kanamycin. ${ }^{19}$ Isaji et al. recently demonstrated in mice fed a choline-deficient, ethionine-supplemented diet to induce pancreatitis that oral antibiotics caused a threefold reduction of infected necrosis and a significantly improved survival. ${ }^{28}$

Several clinical studies have demonstrated that selective decontamination effectively eliminates aerobic gram-negative bacteria from the intestinal tract and sometimes reduces gram-negative septic complications in intensive care unit patients. However, results regarding reduction of mortality are conflicting. ${ }^{29-34}$ This ran-

Supported by a grant from Merck Sharp \& Dohme B.V., the Netherlands, and a grant from Roussel B.V., the Netherlands.

Address reprint requests to Prof. Dr. H.A. Bruining, Department of Surgery, University Hospital Rotterdam-Dijkzigt, Dr. Molewaterplein 40, 3015 GD Rotterdam, the Netherlands.

Accepted for publication September 13, 1994. domized, controlled clinical trial was undertaken to evaluate whether selective decontamination reduces mortality in patients with objective evidence of severe acute pancreatitis.

\section{METHODS}

Between April 22, 1990 and April 19, 1993, 102 patients with objective clinical signs of severe acute pancreatitis were admitted to 16 participating hospitals. The diagnosis of acute pancreatitis had been established on the basis of clinical examination and elevated plasma levels of amylase ( $>1000$ international units/L), or at diagnostic laparotomy (ten patients). All patients were scored according to multiple laboratory criteria (Imrie score) ${ }^{35}$ and contrast-enhanced computed tomography (CE-CT) examinations were used to classify disease severity (Balthazar grades) ${ }^{36}$ within 48 hours of hospital admission (Table 1).

Patients were included in the study if the following criteria were met: severe pancreatitis was indicated by three or more points according to the Imrie score and/or CT findings corresponding with Balthazar grade $\mathrm{D}$ or $\mathrm{E}$.

Findings at diagnostic laparotomy were not accepted as an inclusion criteria. Exclusion criteria were defined as follows: allergy to one of the antibiotics of the selective decontamination regimen; younger than 18 years of age; postoperative pancreatitis after pancreatic surgery; and bacteriologically proven infected necrosis at the time of randomization. The attending clinician obtained informed consent from the patient or relatives.

Patients who satisfied the criteria were randomly assigned to receive standard treatment (control group) or the same standard treatment plus selective decontamination (selective decontamination group). A 24-hour randomization service was available to randomize patients with stratification per center. Follow-up CT scans were repeated every week until discharge or death. The study was approved by the ethics committees of the participating hospitals.

\section{Control Group: Standard Treatment}

A nasogastric tube was always inserted. Intravenous crystalloid solutions were given according to clinical requirements. Oxygen therapy, based on arterial blood gas analysis, was administered by face mask and was re- 


\section{Table 1. PROGNOSTIC SYSTEMS USED TO SELECT PATIENTS FOR INCLUSION IN THE TRIAL}

$\begin{array}{lc}\text { Multiple laboratory criteria (Imrie score) } & \\ \text { Age } & >55 \text { years } \\ \text { Serum uncorrected calcium } & <2.00 \mathrm{mmol} / \mathrm{l} \\ \text { Serum urea } & >16 \mathrm{mmol} / \mathrm{l} \\ \mathrm{LDH} & >600 \mathrm{U} / \mathrm{l} \\ \text { Blood glucose (no diabetes) } & >10 \mathrm{mmol} / \mathrm{l} \\ \text { WBC } & >1510^{9} / \mathrm{l} \\ \text { Serum albumin } & <32 \mathrm{~g} / \mathrm{l} \\ \mathrm{PaO}_{2} & <60 \mathrm{~mm} \mathrm{Hg}(7.5 \mathrm{kPa})\end{array}$

Degree of disease severity according to Balthazar classification†

$\begin{array}{ll}\text { Grade A } & \text { Normal pancreas. } \\ \text { Grade B } & \text { Focal or diffuse enlargement of the pancreas } \\ \text { (including contour irregularities, } \\ \text { nonhomogeneous attenuation of the } \\ \text { gland, dilatation of the pancreatic duct, } \\ \text { and foci of small fluid collections within the } \\ \text { gland, as long as there is no evidence of } \\ \text { peripancreatic disease). } \\ \text { Intrinsic pancreatic abnormalities associated } \\ \text { with haziness and streaky densities } \\ \text { representing inflammatory changes in the } \\ \text { peripancreatic fat. } \\ \text { Grade C } \\ \text { As C plus single ill-defined fluid collection } \\ \text { (phlegmon) in or adjacent to the pancreas. } \\ \text { As C plus two or multiple, poorly defined fluid } \\ \text { collections or the presence of gas in or } \\ \text { adjacent to the pancreas. }\end{array}$

$\mathrm{LDH}=$ lactate dehydrogenase WBC $=$ white blood cell count $\mathrm{PaO}_{2}=$ arterial oxy gen concentration.

" The Imrie score equals the number of separate criteria present (minimum: 0; maximum: 8).

† Computed tomography scan with use of oral ( $1 / 2$ hour before) and intravenous contrast (rapid intravenous drip).

placed by assisted ventilation if the patient developed respiratory insufficiency. Cultures from the oropharynx, rectum, sputum, gastric content, and urine were taken on admission to the hospital and twice a week until discharge. If fever $(\geq 39 \mathrm{C})$ was present, blood cultures were taken. Except for urine, qualitative semiquantitative bacteriologic analysis was performed routinely on all cultures. Cultures of pancreatic necrosis and ascites were obtained at laparotomy or by means of ultrasonography or CT-guided percutaneous puncture, as described by Gerzoff et al., ${ }^{10}$ if there was clinical suspicion of infected pancreatic necrosis. Patients underwent surgery if an ultrasongographic or CT-guided puncture showed presence of bacteria or if the condition was deteriorating despite aggressive supportive treatment. Surgery was performed either by transverse or median laparotomy. If repeated laparotomies were foreseen, a laparostomy, i.e., a ventral open packing of the abdominal cavity, was created. ${ }^{2}$ Antibiotics were prescribed according to the antibiogram only in the presence of concurrent infection. Enteral feeding was replaced by total parenteral nutrition only if recurrent gastric retention was present.

\section{Selective Decontamination Group: Standard Treatment with Adjuvant Selective Decontamination}

Patients randomized to the selective decontamination group received the same treatment as the control group with the addition of selective decontamination. The selective decontamination regimen consisted of oral administration of colistin sulfate $(200 \mathrm{mg})$, amphotericin $(500 \mathrm{mg}$ ) and norfloxacin (Noroxin, Merck \& Co., West Point, PA; $50 \mathrm{mg}$ ) every 6 hours. A sticky paste containing $2 \%$ of the three selective decontamination drugs was smeared along the upper and lower gums every 6 hours and at the tracheostomy, if present. The aforementioned daily dose also was given in a rectal enema every day. A short-term systemic prophylaxis of cefotaxime sodium (Claforan, Hoechst-Roussel Pharm., Inc., Somerville, $\mathrm{NJ} ; 500 \mathrm{mg}$ ) was given every 8 hours until gram-negative bacteria were eliminated from the oral cavity and rectum. Selective decontamination was discontinued as soon as the risk of acquiring a new infection was absent-i.e., the patient was extubated and without supplementary oxygen therapy or infusions, on regular oral diet, and mobilized on the ward.

\section{Statistical Analysis}

Power calculations at the phase of trial design, assuming a decrease in mortality from $50 \%$ to $25 \%$, led to a total number of 154 patients to be included (alpha $=0.05$ [two-sided] and beta $=0.10$ ).

Because the annual accrual rate was much less than expected, after 2 years it was decided to limit the size of the trial to 100 evaluable patients, thereby reducing the power to $80 \%$ at one-sided testing. This decision was made without consideration of the accumulating outcomes.

Percentages were compared by the Fisher exact test or the chi square test, if appropriate. Continuous data were compared by the Mann-Whitney $U$ test. For mortality, which was the major endpoint in this study, multivariate analysis (logistic regression ${ }^{37}$ ) at entry into the study, allowing for Imrie score and Balthazar grade, was performed to obtain a higher level of precision in comparing treatment groups. Two-sided $p$ values of 0.05 or less were 
considered statistically significant. Follow-up was continued until death or discharge from the hospital.

\section{RESULTS}

\section{Inclusions, Exclusions, and Withdrawals}

Of the 109 patients randomized into the study, 2 (selective decontamination: $n=1$; control: $n=1$ ) were excluded because of perioperatively proven infected necrosis immediately ( $<1$ hour) after randomization and before treatment was started. In addition, five patients (selective decontamination: $n=3$; control: $n=2$ ) were withdrawn from the study because the clinical diagnosis was found to be erroneous (one patient with streptococcal sepsis, one patient with an acute aortic occlusion immediately after coronary bypass surgery, one patient with a ruptured pancreatic pseudocyst, one patient with chronic pancreatitis, and one patient with an endoscopic retrograde cholangiopancreatograpy-induced choledochus perforation). Of the remaining 102 patients, 50 had been assigned to the selective decontamination group and 52 to the control group. Inclusion scores are listed in Table 2. Selective decontamination was started within 24 hours of randomization. Ten patients (selective decontamination: $n=8$; control : $n=2$ ) with severe acute pancreatitis had to be randomized only on the basis of the multiple laboratory criteria (Imrie score $\geq 3$ ) because their condition did not permit transport from the intensive care unit to the CT scanner at that time. Of these patients, fluid collections in or adjacent to the severely inflamed pancreas (personal communication with the attending surgeon immediately postoperatively) were demonstrated on the first day of the study during laparotomy in eight patients and with abdominal ultrasound in one patient. Because of these results, the Balthazar grade was classified as grade $\mathrm{E}$. In the other patient (control group; Imrie score $=3$ ), a CT scan was performed only after 5 days of treatment, and it demonstrated a peripancreatic fluid collection. The latter patient also underwent surgery on the first day after randomization; however, the pancreatic loge was left untouched. The Balthazar grade at the time of randomization was unavailable for this patient.

\section{Comparability of Control and Selective Decontamination Group}

Both treatment groups appeared well matched for age, sex, etiologic factors, Imrie score, and Balthazar grade. Characteristics for both groups are listed in Table 2. The mean Imrie score was 3.2 for both groups. Patients with an Imrie score of 8 were not encountered in this study.
Table 2. BASELINE CHARACTERISTICS OF PATIENTS WITH ACUTE NECROTIZING PANCREATITIS

\begin{tabular}{|c|c|c|}
\hline & $\begin{array}{c}\text { Selective } \\
\text { Decontamination } \\
\text { Group } \\
(\mathbf{n}=\mathbf{5 0})\end{array}$ & $\begin{array}{c}\text { Control } \\
\text { Group } \\
(n=52)\end{array}$ \\
\hline Mean age (years) & $56(26-91)$ & $55(20-88)$ \\
\hline \multicolumn{3}{|l|}{ Sex } \\
\hline Male & 31 & 29 \\
\hline Female & 19 & 23 \\
\hline \multicolumn{3}{|l|}{ Etiology } \\
\hline Alcohol & 19 & 12 \\
\hline Gallstones & 17 & 19 \\
\hline Hyperparathyroidism & 0 & 2 \\
\hline Blunt abdominal trauma & 1 & 0 \\
\hline Postoperative & 2 & 2 \\
\hline ERCP-induced & 1 & 3 \\
\hline Unknown & 10 & 14 \\
\hline \multicolumn{3}{|l|}{ Imrie score } \\
\hline 0 & 5 & 4 \\
\hline 1 & 8 & 7 \\
\hline 2 & 2 & 10 \\
\hline 3 & 10 & 6 \\
\hline 4 & 12 & 13 \\
\hline 5 & 9 & 6 \\
\hline 6 & 3 & 2 \\
\hline 7 & 1 & 4 \\
\hline 8 & 0 & 0 \\
\hline \multicolumn{3}{|l|}{$\begin{array}{l}\text { Balthazar degree of disease } \\
\text { severity }\end{array}$} \\
\hline Grade A & 0 & 0 \\
\hline Grade B & 0 & 0 \\
\hline Grade C & 3 & 4 \\
\hline Grade D & 21 & 20 \\
\hline Grade E & 26 & 27 \\
\hline Day 1 unavailable & 0 & $1^{*}$ \\
\hline \multicolumn{3}{|c|}{ ERCP = endoscopic retrograde cholangiopancreatography. } \\
\hline
\end{tabular}

\section{Mortality}

Eleven patients $(22 \%)$ in the selective decontamination group died as compared with 18 patients $(35 \%)$ in the control group. This difference is not significant $(p=$ 0.19). The $95 \%$ confidence limits of the difference (control group minus selective decontamination group) in mortality ranges from less than $4 \%$ to more than $30 \%$. Survival according to treatment group is shown in Figure 1. All deaths occurred within 80 days. In each of both groups, six patients died of multiple-organ failure with documented sterile pancreatic necrosis. Ten patients in the control group died of a gram-negative pancreatic sepsis syndrome compared with only three such patients in the selective decontamination group $(p=0.07)$. In each 


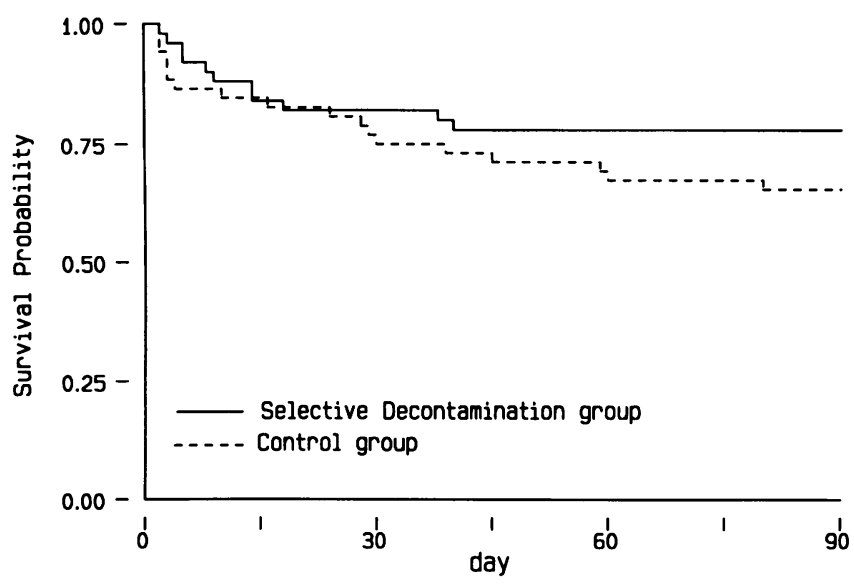

Figure 1. Overall survival according to treatment. Overall mortality rates at 90 days: selective decontamination group $=22 \%$; control group $=$ $35 \%$. Adjusted for Imrie score and Balthazar grade, $p=0.048$. Difference in mortality rates equals $13 \%$ (95\% confidence limits: $-4 \%,+30 \%)$.

group, one patient died of sepsis due to a solitary grampositive pancreatic infection. Gram-positive sepsis of unknown origin, without pancreatic infection, was the cause of death in one patient in each of both groups.

The Imrie score at entry into the study appeared to correlate very strongly with mortality (Fig. 2). Mortality was $0 \%$, for an Imrie score of 0 or 1 , and it gradually increased to $100 \%$, for patients with an Imrie score of 7 $\left(\mathrm{p}_{\text {trend }}<0.001\right)$. Mortality also increased with increasing Balthazar grade, although these differences were less pronounced $\left(p_{\text {trend }}=0.04\right)($ Fig. 2$)$. The worsening of prognosis with increasing Imrie score and Balthazar grade was apparent in each separate treatment group. Overall mortality in the selective decontamination group versus the mortality in the control group appeared to be significantly lower $(p=0.048)$, using multivariate analysis allowing for Imrie score and Balthazar grade (Table 3). This analysis also demonstrates the importance of the Imrie score in predicting mortality. There was no significant relation between mortality and the Balthazar grade.

\section{Bacteriologic Analysis}

Secondary pancreatic infection occurred in 20 patients $(38 \%)$ in the control group and in 9 patients $(18 \%)$ of the selective decontamination group $(p=0.03)$. Gram-negative pancreatic infection occurred in 17 patients $(33 \%)$ in the control group and in only 4 patients $(8 \%)$ in the selective decontamination group $(p=0.003)$. Pancreatic necrosis was not infected in 11 of 16 patients who died early, in contrast to only 3 of 13 patients who died after 2 weeks $(p=0.03)$. This difference is similar for both groups.
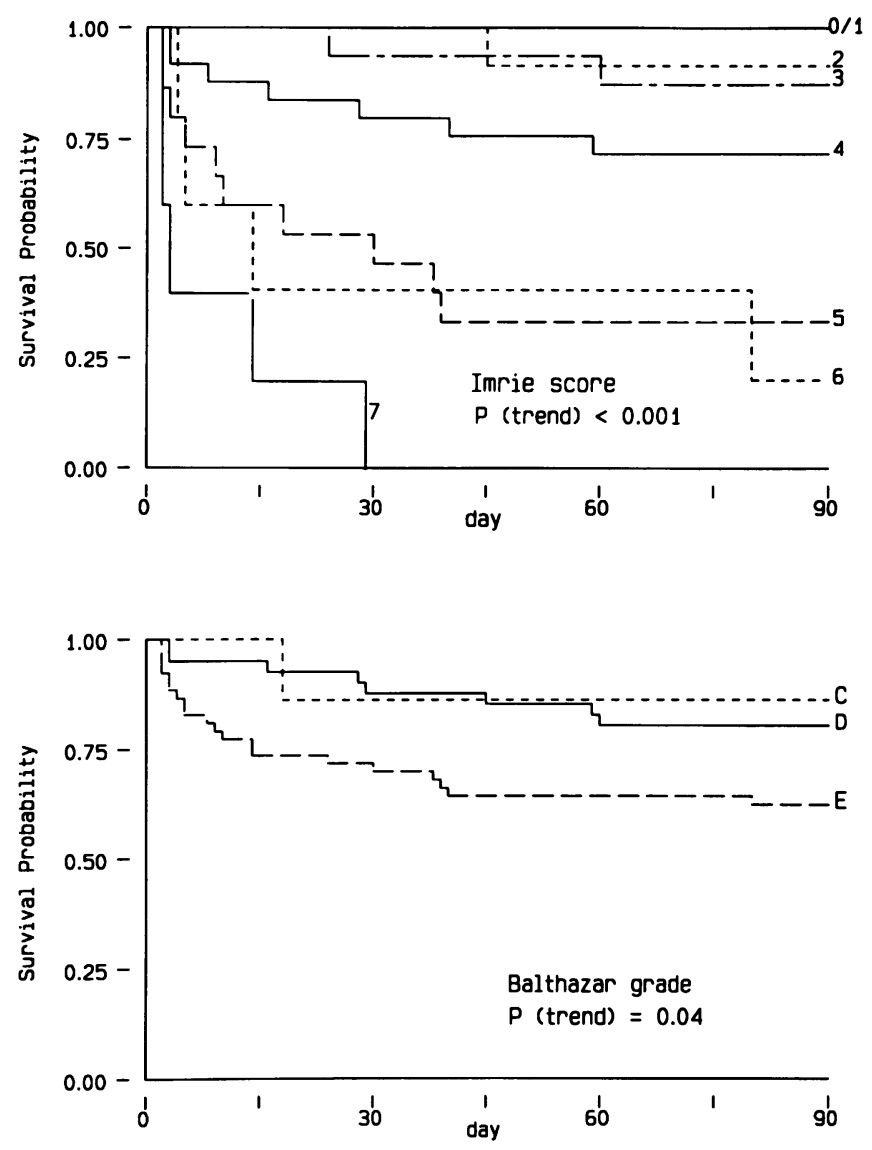

Figure 2. Survival according to an Imrie score of $0 / 1(n=24), 2(n=12)$, $3(n=16), 4(n=25), 5(n=15), 6(n=5)$, and $7(n=5)$, respectively (upper panel). Survival according to Balthazar grade $C(n=7), D(n=41)$, or $E(n=53)$, respectively (lower panel). Both as assessed at entry into the study, for both treatment groups combined. Severe acute pancreatitis was defined according to Imrie score $\geq 3$ points and/or CT findings according to Balthazar's degree of disease severity grade $D$ or $E$.

Table 3. MULTIVARIATE ANALYSIS OF MORTALITY IN RELATION TO TREATMENT, IMRIE SCORE, AND BALTHAZAR GRADE

\begin{tabular}{|c|c|c|}
\hline Factor & $\begin{array}{l}\text { Odds } \\
\text { Ratio }\end{array}$ & p Value \\
\hline \multicolumn{3}{|l|}{ Treatment } \\
\hline Control & $1^{*}$ & - \\
\hline Selective decontamination & $0.3(0.3)$ & $0.048(0.049)$ \\
\hline Imrie score & $3.7 \dagger(3.9)$ & $<0.001(<0.001)$ \\
\hline \multicolumn{3}{|l|}{ Balthazar grade } \\
\hline $\mathrm{C} / \mathrm{D}$ & $1^{\star}$ & - \\
\hline$E$ & $1.8(-)$ & $0.354(-)$ \\
\hline \multicolumn{3}{|c|}{$\begin{array}{l}\text { * Reference category. } \\
\text { † Relative to patients who have an Imrie score of } 1 \text { point less. } \\
\text { Data given are odds-ratios for mortality. (Odds-ratios }>1 \text { indicate an increased mor } \\
\text { tality; }<1 \text { indicate a decreased mortality.) Data between parentheses denote results } \\
\text { when only treatment and Imrie score are analysed regarding mortality. }\end{array}$} \\
\hline
\end{tabular}


Table 4. BACTERIOLOGIC ANALYSIS OF INFECTED NECROSIS PRESENCE OF MICRO-ORGANISMS*

\begin{tabular}{lcc}
\hline \multicolumn{1}{c}{ Species } & $\begin{array}{c}\text { Selective } \\
\text { Decontamination } \\
\text { Group } \\
\text { (n= 9) }\end{array}$ & $\begin{array}{c}\text { Control Group } \\
\text { (n= 20) }\end{array}$ \\
\hline Gram negative aerobic & - & \\
Acinetobacter spp. & - & 3 \\
Citrobacter spp. & 1 & 3 \\
Escherichia coli & - & 12 \\
Enterobacter spp. & 1 & 5 \\
Klebsiella spp. & 3 & 5 \\
Pseudomonas spp. & - & 10 \\
Proteus spp. & - & 2 \\
Morganella spp. & 1 & 4 \\
Serratia maresc. & - & - \\
Alicaligenes spp. & - & 1 \\
Gram positive aerobic & - & 1 \\
Staphylococci spp. & 4 & 4 \\
Staph. aureus & 9 & 12 \\
Staph. epidermidis & 2 & - \\
Streptococci & 7 & 12 \\
Enterococci & & \\
Yeasts & & \\
Candida albicans & & \\
* Micro-organisms may occur in combinations in each separate patient. & \\
\hline
\end{tabular}

Qualitative bacteriologic analysis of (peri-) pancreatic necrosis for both groups is demonstrated in Table 4. Of 74 bacterial colonies isolated from 20 patients of the control group, $61 \%$ were aerobic gram-negative pathogens. Of 28 colonies isolated from nine patients of the selective decontamination group, $21 \%$ were aerobic gram-negative. Any case of gram-negative pancreatic infection was preceded by intestinal colonization with identical gramnegative flora in both groups, as learned from surveillance cultures of the digestive tract.

\section{Selective Decontamination Regimen: Complications and Failure of Selective Decontamination Because of Resistance}

There were no noticeable allergies in the selective decontamination regimen, and none of the deaths in the selective decontamination group were attributable to the selective decontamination regimen. Oral paste and rectal enemas were well tolerated. Gram-negative colonization of the digestive tract was successfully prevented in 46 of 50 patients $(92 \%)$ of the selective decontamination group. However, failure of selective decontamination to prevent gram-negative colonization of the digestive tract with subsequent infection of pancreatic necrosis with the same gram-negative bacteria was seen in 4 of 50 patients $(8 \%)$. Three of these patients died after 9,37 , and 40 days due to resistant strains of Pseudomonas aeruginosa (two patients) and Klebsiella (one patient). Escherichia coli $(<1+)$ was isolated only once from pancreatic necrosis in one of these patients at the end of the first week because of initial persistence of intestinal $E$. coli. Transient gram-negative pancreatic infection during selective decontamination treatment was seen in one patient-i.e., $P$. aeruginosa ( $<3$ days), followed by Serratia marcescens $(<18$ days) - who was later discharged after 106 days.

\section{Surgery and Surgery-Related Morbidity}

In the control group, an average of 3.1 laparotomies were performed per patient in contrast to only 0.9 in the selective decontamination group ( $p<0.05$; Table 5$)$. A laparostomy, whenever repeated necrosectomy was foreseen, was created in $50 \%$ of the patients in both groups. In the control group, surgical complications were seen in nine patients, compared with four patients of the selective decontamination group, who had undergone surgery less frequently ( $p=0.50, \mathrm{NS}$ ).

Median hospital stay in patients who survived was 30 days (range 10-106 days) in the selective decontamination group compared with 32 days (range 6-241 days) in the control group $(p=0.65, N S)$.

Table 5. SURGERY AND SURGICAL MORBIDITY

\begin{tabular}{|c|c|c|}
\hline & $\begin{array}{c}\text { Selective } \\
\text { Decontamination } \\
\text { Group } \\
(\mathbf{n}=\mathbf{5 0})\end{array}$ & $\begin{array}{l}\text { Control } \\
\text { Group } \\
(\mathbf{n}=\mathbf{5 2})\end{array}$ \\
\hline Laparotomy & $16(32 \%)$ & $24(46 \%)$ \\
\hline $\begin{array}{l}\text { Laparotomies/patient } \\
\text { (range) }\end{array}$ & $0.9^{\star}(0-17)$ & $3.1^{\star}(0-29)$ \\
\hline \multicolumn{3}{|l|}{ Patients with surgery-related } \\
\hline \multicolumn{3}{|l|}{ Complications $†$} \\
\hline Small bowel resections & 0 & 5 \\
\hline Large bowel resections & 1 & 7 \\
\hline Enteric fistulas & 2 & 6 \\
\hline Pancreatic fistulas & 2 & 2 \\
\hline Splenectomy & 0 & 3 \\
\hline \multicolumn{3}{|c|}{$\begin{array}{l}{ }^{*} p<0.05 \text {. } \\
\text { † Complications may occur in combinations in each separate patient. Laparostomies } \\
\text { were created in } 8 \text { out of } 16 \text { patients in the selective decontamination group and in } \\
12 \text { out of } 24 \text { patients in the control group. }\end{array}$} \\
\hline
\end{tabular}




\section{DISCUSSION}

The division of acute necrotizing pancreatitis into an early vasoactive toxic phase and a late phase dominated by septic complications is widely accepted. ${ }^{9,38-40}$ Systemic complications during the initial phase of circulatory depression, such as myocardial depression and acute renal and respiratory failure, are thought to be mediated by activated pancreatic enzymes and other vasoactive and toxic agents released from the pancreas and the peritoneal exudate. ${ }^{38,41,42}$ Intensive treatment has improved the prognosis with regard to these complications, which previously were the major cause of death during the early phase of acute necrotizing pancreatitis. ${ }^{38,43,44}$

Secondary infection of pancreatic necrosis currently is the most lethal complication of acute necrotizing pancreatitis, particularly during the later stages of the disease. ${ }^{2,9-13,17,20,38,45}$ Gram-negative aerobic bacteria, originating from the digestive tract, are predominantly isolated from infected pancreatic necrosis. ${ }^{914,19,23,26} \mathrm{Re}-$ cently, Medich et al. reported that acute pancreatitis in rats promotes translocation of gastrointestinal organisms to the inflamed pancreas and peripancreatic region. ${ }^{27}$ Widdison et al. reported striking results from a feline model, suggesting gut-derived pancreatic infection by showing that labeled intestinal $E$. coli were not recovered from the site of acute necrotizing pancreatitis when the colon was enclosed in an impermeable bag that prohibited translocation. ${ }^{22}$

Until now, the beneficial effect of prophylactic antibiotics in acute pancreatitis has been debated. $.^{12,15,16} \mathrm{Re}-$ cently, Pederzoli et al. reported that prophylactic treatment with intravenous imipenem significantly reduced the incidence of infected necrosis $(12.2 \%)$ as compared with placebo (30.3\%). However, no significant reduction in mortality could be demonstrated. ${ }^{46}$ If increased bacterial translocation from the digestive tract is the mechanism leading to pancreatic infection, selective decontamination should, in theory, be useful in preventing pancreatic sepsis. ${ }^{27} \mathrm{McClelland}$ et al. ${ }^{31}$ reported a significant reduction in clinical signs of sepsis in patients with acute pancreatitis and acute respiratory failure who were treated with selective decontamination. No significant reduction in mortality, however, was demonstrated from this retrospective analysis comprising only six selective decontamination patients in a 3-year period, who were compared with nine historic control patients from an earlier 3-year period. Reduction of mortality in intensive care unit patients treated with adjuvant selective decontamination still is a matter of debate,${ }^{29-34}$ and randomized controlled clinical trials of selective decontamination in the treatment of patients with severe acute pancreatitis currently are not available. In the prospective clinical trials reported to date, only a few patients had severe acute pancreatitis or developed pancreatic sepsis. In the present study, selective decontamination significantly $(p=0.003)$ reduced the incidence of gram-negative pancreatic sepsis. Consequently, a significant reduction in the number of laparotomies having fewer surgeryrelated complications occurred in patients treated with selective decontamination.

Because infection of originally sterile pancreatic necrosis is a secondary phenomenon, effective antibiotic prophylaxis may result mainly in reduction of late mortality. Early mortality, rather dominated by effects of vasoactive and toxic agents released from the pancreas and peritoneal exudate than by septic complications, may consequently be less reduced by antibiotics. ${ }^{38-42}$ This may explain why selective decontamination, reducing total mortality, did not affect early mortality (within 2 weeks) as appeared on further analysis (selective decontamination: $16 \% ; 8 / 50$ patients; control: $15 \% ; 8 / 52$ patients) $(p=0.71)$. Late mortality, on the other hand, was significantly reduced by selective decontamination (selective decontamination: $7 \% ; 3 / 42$ patients; control: $23 \% ; 10 / 44$ patients). In both groups, all gram-negative pancreatic infections, if present, were preceded by colonization of the digestive tract with the same gram-negative bacteria. If pancreatic necrosis was infected despite successful selective decontamination, only gram-positive aerobic bacteria were isolated, as has also been noted by others. ${ }^{47}$ If selective decontamination fails, however, mortality increases sharply, which has been recognized earlier in surgical intensive care patients. ${ }^{48}$

Severity scoring of acute pancreatitis immediately after admission has previously been strongly advocated to identify patients at risk..$^{35,36,49-51}$ It also enables clinicians to compare treatment results more accurately. Scoring systems should be accurate but easy to use. The Imrie score proved to be very valuable in identifying patients with acute pancreatitis with increased risk of death. Computed tomography findings, according to Balthazar's degree of disease severity, were less accurate in predicting prognosis. Total mortality of patients who were found to have severe acute pancreatitis according CT findings alone (Balthazar grade D or E, but Imrie score $<3$ ) was less than $5 \%$ in each group. These data suggest that the use of selective decontamination in such patients may not result in additional benefit and is cost-inducing.

We conclude that selective decontamination is especially indicated for patients with severe acute pancreatitis with an Imrie score $\geq 3$, regardless of the CT findings ${ }^{36}$ on admission. Treated as such, in this study, total mortality was reduced from $55 \%$ (17/31 patients) to $31 \%$ (11/ 35 patients), with a $95 \%$ confidence interval for the difference in mortality ranging from $0 \%$ to $48 \%$. 


\section{Acknowledgments}

The authors thank the following surgical colleagues at the participating centers: W. F. Eggink, Rijnstate Ziekenhuis, Arnhem; A. C. van der Ham, St. Jansdal Ziekenhuis, Harderwijk; A. Jansen, St. Antonius Ziekenhuis, Nieuwegein; J. H. C. Kuypers and A. P. M. Boll, St. Radboudziekenhuis, Nijmegen; J. Lens and R. J.Th. J. Welten, De Wever Ziekenhuis, Heerlen; H. Obertop and R. Trompmeesters, Academisch Ziekenhuis, Utrecht; H. B. Oeseburg, Martini Ziekenhuis, Groningen; M. K. M. Salu, Zuiderziekenhuis, Rotterdam; H. L. de Smet, St. Maartens Gasthuis, Venlo; J. P. Snellen, Kennemer Gasthuis, Haarlem; Th. J. van Straaten, St.Jozef Ziekenhuis, Veldhoven; H. F. Veen, Ikazia Ziekenhuis, Rotterdam; W. R. Weidema, Reinier de Graaf Gasthuis, Delft; and J. C. J. Wereldsma, St. Franciscus Gasthuis, Rotterdam. They also thank Mr. J. Arnold, Ph.D.; Mrs. H. Berger-Lahade, M.D.; Mr. H. A. Brummelman, M.D. (Roussel B.V.); Ms. G. J. Gamelkoorn, Ph.D. (M.S.D. B.V.); and Ms. H. H. M. Stege, secretary, for their assistance.

\section{References}

1. Beger HG. Operative management of necrotizing pancreatitisnecrosectomy and continuous closed postoperative lavage of the lesser sac. Hepatogastroenterology 1991; 38:129-133.

2. Bradley EL 3d. Operative management of acute pancreatitis: ventral open packing. Hepatogastroenterology 1991; 38:134-138.

3. Kivilaakso E, Lempinen M, Makelainen A, et al. Pancreatic resection versus peritoneal lavation for acute fulminant pancreatitis: a randomized prospective study. Ann Surg 1984; 199:426-431.

4. D'Egidio A, Schein M. Surgical strategies in the treatment of pancreatic necrosis and infection. Br J Surg 1991; 78:133-137.

5. Ranson JH. The timing of biliary surgery in acute pancreatitis. Ann Surg 1979; 189:654-663.

6. Pemberton JH, Becker JM, Dozois RR, et al. Controlled open lesser sac drainage for pancreatic abscess. Ann Surg 1986; 203:600604.

7. Warshaw AL, Jin GL. Improved survival in 45 patients with pancreatic abscess. Ann Surg 1985; 202:408-417.

8. Allardyce DB. Incidence of necrotizing pancreatitis and factors related to mortality. Am J Surg 1987; 154:295-299.

9. Beger HG, Bittner R, Block S, et all. Bacterial contamination of pancreatic necrosis: a prospective clinical study. Gastroenterology 1986; 91:433-438.

10. Gerzof SG, Banks PA, Robbins AH, et al. Early diagnosis of pancreatic infection by computed tomography-guided aspiration. Gastroenterology 1987; 93:1315-1320.

11. Beger HG. Surgery in acute pancreatitis. Hepatogastroenterology 1991; 38:92-96.

12. Bradley EL 3d. Antibiotics in acute pancreatitis: current status and future directions. Am J Surg 1989; 158:472-477.

13. Fernandez-del Castillo C, Rattner DW, Warshaw AL. Acute pancreatitis. Lancet $1993 ; 342: 472-479$.

14. Lumsden A, Bradley EL 3d. Secondary pancreatic infections. Surg Gynecol Obstet 1990; 170:P 459-467.

15. Finch WT, Sawyers JL, Schenker S. A prospective study to determine the efficacy of antibiotics in acute pancreatitis. Ann Surg 1976; 183:667-671.

16. Howes R, Zuidema GD, Cameron JL. Evaluation of prophylactic antibiotics in acute pancreatitis. J Surg Res 1975; 18:197-200.

17. Kodesch R, DuPont HL. Infectious complications of acute pancreatitis. Surg Gynecol Obstet 1973; 136:763-768.

18. Webster MW, Pasculle AW, Myerowitz RL, et al. Postinduction bacteremia in experimental acute pancreatitis. Am J Surg 1979; 138:418-420.

19. Lange JF, van Gool J, Tytgat GN. The protective effect of a reduction in intestinal flora on mortality of acute haemorrhagic pancreatitis in the rat. Hepatogastroenterology $1987 ; 34: 28-30$.

20. Warshaw AL. Inflammatory masses following acute pancreatitis. Phlegmon, pseudocyts, and abscess. Surg Clin North Am 1974; 54 : 621-636.

21. Wells CL, Rotstein OD, Pruett TL, et al. Intestinal bacteria translocate into experimental intra-abdominal abcesses. Arch Surg 1986; 121:102-107.

22. Widdison AL, Karanjia ND, Alvarez C, et al. Sources of pancreatic pathogens in acute necrotizing pancreatitis. Gastroenterology 1991; 100:A304.

23. Tarpila E, Nystrom PO, Franzen L, et al. Bacterial translocation during acute pancreatitis in rats. Eur J Surg 1993; 159:109-1 13.

24. Konok GP, Thompson AG. Pancreatic ductal mucosa as a protective barrier in the pathogenesis of acute pancreatitis. Am J Surg 1969; 117:18-23.

25. Byrne JJ, Joison J. Bacterial regurgitation in experimental pancreatitis. Am J Surg 1964; 107:317-320.

26. Runkel NS, Moody FG, Smith GS, et al. The role of the gut in the development of sepsis in acute pancreatitis. J Surg Res 1991; 51: 18-23.

27. Medich DS, Lee TK, Melhem MF, et al. Pathogenesis of pancreatic sepsis. Am J Surg 1993; 165:46-52.

28. Isaji S, Suzuki M, Frey CF, et al. Role of bacterial infection in dietinduced acute pancreatitis in mice. Int J Pancreatol 1992; 11:4957.

29. Stoutenbeek CP, van Saene HK, Miranda DR, et al. The effect of selective decontamination of the digestive tract on colonisation and infection rate in multiple trauma patients. Intensive Care Med 1984; 10:185-192.

30. Tetteroo GW, Wagenvoort JH, Castelein A, et al. Selective decontamination to reduce gram-negative colonisation and infections after oesophageal resection. Lancet 1990; 335:704-707.

31. McClelland P, Murray A, Yaqoob M, et al. Prevention of bacterial infection and sepsis in acute severe pancreatitis. Ann R Coll Surg Engl 1992; 4:329-334.

32. Rocha LA, Martin MJ, Pita S, et al. Prevention of nosocomial infection in critically ill patients by selective decontamination of the digestive tract; a randomized double blind, placebo-controlled study. Int Care Med 1992; 18:389-404.

33. Gastinne H, Wolff M, Delatour F, et al. A controlled trial in intensive care units of selective decontamination of the digestive tract with nonabsorbable antibiotics. N Engl J Med 1992; 326:594-599.

34. Cerra FB, Maddaus MA, Dunn DL, et al. Selective gut decontamination reduces nosocomial infections and length of stay but not mortality or organ failure in surgical intensive care unit patients. Arch Surg 1992; 127:163-167.

35. Blamey SL, Imrie CW, O’Neill J, et al. Prognostic factors in acute pancreatitis. Gut 1984; 25:1340-1346.

36. Balthazar EJ, Ranson JH, Naidich DP, et al. Acute pancreatitis: prognostic value of CT. Radiology 1985; 156:767-772.

37. Cox DR. The Analysis of Binary Data. London: Methuen, 1970.

38. Wilson C, Imrie CW. Systemic effects of acute pancreatitis. In Johnson CD, Imrie CW. Pancreatic Disease. 1st ed. London: Springer Verlag, 1991, pp 287-297.

39. Karimgani I, Porter KA, Langevin RE. Prognostic factors in sterile pancreatic necrosis. Gastroenterology 1992; 103:1636-1640.

40. Warshaw AL, Imbembo AL, Civetta JM, et al. Surgical intervention in acute necrotizing pancreatitis. Am J Surg 1974; 127:484491. 
41. Imrie CW. Observations on acute pancreatitis. Br J Surg 1974; 61: 539-544.

42. Ranson JH, Turner JW, Roses DF, et al. Respiratory complications in acute pancreatitis. Ann Surg 1974; 179:557-566.

43. Trapnell JE. The natural history and prognosis of acute pancreatitis. Ann R Coll Surg Engl 1966; 38:265-287.

44. Imrie CW, Blumgart LH. Acute pancreatitis: a prospective study on some factors in mortality. Bull Soc Int Chir 1975; 34:601-603.

45. Ranson JHC, Balthazar E, Caccavale R, et al. Computed tomography and the prediction of pancreatic abscess in acute pancreatitis. Ann Surg 1985; 201:656-665.

46. Pederzoli P, Bassi C, Vesentini S, et al. A randomized multicenter clinical trial of antibiotic prophylaxis of septic complications in acute necrotizing pancreatitis with imipenem. Surg Gynecol Obst 1993; 176:480-483.
47. Jackson RJ, Smith SD, Rowe MI. Selective bowel decontamination results in gram-positive translocation. J Surg Res 1990; 48: 444-447.

48. Tetteroo GW, Wagenvoort JH, Mulder PG, et al. Decreased mortality rate and length of hospital stay in surgical intensive care unit patients with successful selective decontamination of the gut. Crit Care Med 1993; 21:1692-1698.

49. Wilson C, Heath Dl, Imrie CW. Prediction of outcome in acute pancreatitis: a comparative study of APACHE II, clinical assessment and ultiple factor scoring systems. Br J Surg 1990; 77:12601264.

50. Larvin M, McMahon MJ. APACHE-II score for assessment and monitoring of acute pancreatitis. Lancet 1989; 2:201-205.

51. Ranson JH, Rifkind KM, Roses DF, et al. Objective early identification of severe acute pancreatitis. Am J Gastroenterol 1974; 61: 443-451. 